\title{
Construção do conhecimento e do fazer enfermagem e os modelos assistenciais*
}

\author{
HEALTH CARE MODELS AND THE BUILDING OF NURSING KNOWLEDGE AND PRACTICE \\ CONSTRUCCIÓN DEL CONOCIMIENTO Y DEL QUEHACER EN ENFERMERÍA \\ YLOS MODELOS ASISTENCIALES
}

\section{Amália de Fátima Lucena1, Lisiane Manganelli Girardi Paskulin², Mariana Fernandes de Souza ${ }^{3}$, Maria Gaby Rivero de Gutiérrez ${ }^{4}$}
* Artigo desenvolvido durante a realização da Disciplina "Cons- trução do Conheci- mento em Enferma- gem, do curso de Doutorado em Enfer- magem/UNIFESP/ EPM, sob a orienta- ção das Professoras Dras. Mariana Fernan- des de Souza e Maria Gaby Rivero Gutiérrez
1 Professora Assis- tente da Escola de Enfermagem da Universidade Fede- ral do Rio Grande do Sul (UFRGS). Doutoranda em Enfermagem pela UNIFESP/EPM. fatimalucena@ terra.com.br;
2 Professora Assis- tente da Escola de Enfermagem da UFRGS. Doutoranda em Enfermagem pela UNIFESP/EPM. paskulin@orion.ufrgs.br
3 Professor Titular do
Departamento de Enfermagem da UNIFESP/EPM.
4 Professor Adjunto do Departamento de Enfermagem da UNIFESP/EPM.

\section{RESUMO}

Artigo de reflexão que enfoca as origens e as principais características dos modelos clínico e epidemiológico, seus nexos com os modelos assistenciais vigentes no sis]tema de saúde brasileiro, e a construção do conhecimento da enfermagem nesse contexto. Nessa perspectiva, as autoras propõem um repensar acerca do saber/fazer da enfermagem, apontando possibilidades de expansão do seu campo de atuação, bem como dos limites e desafios a serem vencidos pelos profissionais da área.

\section{DESCRITORES}

Conhecimento.

Modelos organizacionais.

Prestação de cuidados de saúde. Enfermagem.

\section{ABSTRACT}

This is a reflective paper focused on the origins and main characteristics of the epidemiological and clinical models, their connections with the health care models currently adopted in Brazil, and the construction of Nursing knowledge in this context. From this perspective, the authors propose a re-thinking of Nursing knowledge and practice, pointing out possibilities for expanding the Nursing field, as well as the boundaries and challenges to be overcome by the area professionals.

\section{KEY WORDS}

Knowledge.

Models, organizational.

Delivery of health care.

Nursing.

\section{RESUMEN}

El presente artículo de reflexión enfoca los orígenes y las principales características de los modelos clínico y epidemiológico, sus nexos con los modelos asistenciales vigentes en el sistema de salud brasileño, y la construcción del conocimiento de la enfermería en ese contexto. Bajo esa perspectiva, las autoras proponen un repensar acerca del saber/hacer de la enfermería, apuntando posibilidades de expansión de su campo de actuación, así como de los límites y desafíos a ser vencidos por los profesionales del área.

\section{DESCRIPTORES}

Conocimiento.

Modelos organizacionales.

Prestación de cuidados de salud. Enfermería. 


\section{INTRODUÇÃO}

A motivação em desenvolver esta reflexão surge do cotidiano das autoras, enquanto enfermeiras assistenciais e docentes, atuando em instituições públicas nas áreas de atenção básica à saúde, ambulatorial e hospitalar. Nestes espaços, convivendo com os clientes, estudantes e pares profissionais, deparam-se com as contradições do fazer/educar evidenciadas por uma prática que, ao mesmo tempo em que procura a transformação do modelo assistencial hegemônico, o confirma ou mantém na própria ação. Surge então, o desafio de se (re)pensar o conhecimento da enfermagem, durante uma das disciplinas do curso de doutorado/UNIFESP, em que as autoras deste trabalho propõem aproximar os referenciais dos modelos assistenciais à construção do conhecimento da enfermagem, abordando seus nexos e possibilidades de mudança.

\section{OS MODELOS ASSISTENCIAIS E A CONSTRUÇÃO DO CONHECIMENTO DAENFERMAGEM}

Modelo assistencial é uma construção histórica, política e social, organizada num contexto dinâmico, para atender aos interesses de grupos sociais. É uma forma de organização do Estado e da sociedade civil, instituições de saúde, trabalhadores e empresas que atuam no setor para produzir serviços de saúde ${ }^{(1)}$.

Modelos assistenciais são ainda descritos como uma racionalidade, um modo de combinar tecnologias materiais e não materiais utilizadas nos serviços de saúde, visando o enfrentamento de problemas individuais e coletivos, num determinado território para determinadas populações ${ }^{(2-3)}$.

As conceituações de modelo assistencial permitem vislumbrar diferentes formas de intervenção sobre a realidade de saúde. Para isto, considera-se pertinente analisar o contexto histórico e porque não dizer a gênese do surgimento destes modelos, bem como a inserção da enfermagem enquanto profissão de saúde, que desempenha importante papel, não só na construção, mas também na implantação e manutenção destes modelos.

Para tanto, utiliza-se da perspectiva político-econômica referida por Almeida e Rocha ${ }^{(4)}$, que descrevem em seu estudo o nascimento do modelo clínico no final do século XVIII, paralelo ao surgimento do capitalismo, num movimento social de transformação do hospital, enquanto local e instrumento de cura. As transformações sociais advindas do capitalismo fizeram com que o corpo humano passasse a ser visto como uma fonte de lucro, tanto para quem cuidava como para quem era cuidado, pois se constituía numa força de trabalho. Este contexto, onde o controle a esta força aparece como necessário, utiliza-se da saúde como um dos me- canismos capazes de possibilitar essa tarefa, com vistas a um projeto maior, ou seja, a produção.

A partir disso o modelo clínico vai se delineando, através de seu instrumento e objeto de trabalho, quais sejam, o saber anátomo-fisiológico e o corpo doente. A finalidade neste modelo é a recuperação do corpo individual, sendo o médico a sua figura central, que através do saber clínico em suas ações de diagnóstico e terapêutica produz a recuperação deste corpo. Inicialmente, o médico desempenha sozinho todas as etapas do processo de trabalho, no entanto, a complexidade do conhecimento e a ampliação da infra-estrutura hospitalar levam à necessidade de agregar outros trabalhadores e, conseqüentemente, separar o trabalho em momentos intelectuais e manuais, cabendo ao médico a apropriação do intelectual, o que lhe confere um espaço de poder sobre os demais trabalhadores em saúde. Nesta perspectiva, coube à enfermagem o trabalho manual e esta aparece como parte do trabalho médico, sendo a sua ação um instrumento que cuida ou faz cuidar do corpo doente ${ }^{(4)}$.

O poder sobre a vida desenvolve-se a partir do século XVII nas disciplinas anátomo-políticas centradas no corpo humano como máquina, ocupando-se do seu adestramento, ampliação de aptidões e extorsão de suas forças, integrados em sistemas de controle e econômicos ${ }^{(5)}$.

O corpo humano é visto como uma máquina e suas peças, sendo a doença o mau funcionamento de mecanismos biológicos e, o papel dos médicos a intervenção para consertar o defeito de um determinado mecanismo danificado. Nessa perspectiva, perde-se de vista o indivíduo como ser humano e essa análise reducionista não fornece a compreensão completa e profunda dos seus problemas ${ }^{(6)}$.

Nesse contexto, os progressos da biologia no século XIX foram acompanhados pela tecnologia médica, com novos instrumentos de diagnóstico e tratamento, ao mesmo tempo em que a atenção do médico se transferia do paciente para a doença, iniciando-se assim as especializações, as quais atingem seu auge no século $\mathrm{XX}^{(6)}$.

Desse modo, é junto ao surgimento do modelo clínico e o movimento capitalista, como resultado de transformações sociais, modo de vida e concepções políticas e econômicas da época, que emergem as idéias de Florence Nightingale. Neste período, durante sua atuação na Guerra da Criméia, ela buscou maneiras de organizar o trabalho de enfermagem e de estabelecer intervenções capazes de melhorar a qualidade dos cuidados prestados, bem como, contribuir para garantir a vida de muitos $^{(7)}$.

Esse fato marcante caracteriza o surgimento da Enfermagem Moderna e o rápido abandono da enfermagem domiciliar, anteriormente predominante, para o ambiente hospitalar. A partir disso, a enfermagem passa organizar-se no sentido de, também, buscar maneiras para desenvolver um cor- 
po de conhecimentos próprios que, ainda hoje, sofre a influência do modelo clínico.

A influência desse modelo à enfermagem enquanto disciplina, deu-se em seus instrumentos e objeto de trabalho, conforme afirmado por alguns autores, que reforçam as idéias de que o corpo individual, objeto de trabalho do processo de trabalho médico, passa conseqüentemente também a ser o objeto da atividade de cuidar da enfermagem, que utiliza instrumentos de trabalho também semelhantes para sua ação de cuidar. Do mesmo modo que o objeto, a finalidade deste cuidar é a mesma do trabalho médico, ou seja, curar corpos individuais ${ }^{(4-8)}$.

As influências desse modelo na enfermagem ainda são descritas, de certa forma, pela interpretação e trajetória do cuidado na enfermagem, que aqui se pode traduzir como uma forma de conhecimento. Esse é abordado sob diversos prismas, dentre eles as questões históricas, as influências do capitalismo, bem como, do próprio modelo de saúde.

Por influência do capitalismo e, por conseguinte, do modelo clínico, a enfermagem brasileira, assim como a de outros países, passa a desvalorizar o cuidado, atendendo a uma ideologia de cura, deixando-se ocupar por ações curativas, utilizando-se de tecnologias cada vez mais sofisticadas. $\mathrm{O}$ ensino é realizado com ênfase nas técnicas de enfermagem, onde a habilidade manual, a capacidade de memorização, a postura e a mecânica corporal no desenvolvimento das técnicas são imprescindíveis, além do capricho, organização e perfeição. O objeto da enfermagem deixa de ser o cuidado centrado no paciente, para centrar-se na tarefa a ser executada ${ }^{(9)}$.

Na enfermagem brasileira há outro aspecto diferencial a ser considerado, já que as enfermeiras afastam-se dos pacientes e do cuidado direto ao serem solicitadas, por sua formação universitária e ao reduzido número, para tarefas de liderança de equipe, organização e planejamento ${ }^{(9)}$.

Sobre esse ponto, outros autores ${ }^{(4)}$ colocam que o administrar, que é realizado apenas pela enfermeira e não pelas demais categorias de enfermagem, utiliza-se de instrumentos como os modelos de administração, normas e rotinas, força de trabalho dos auxiliares, equipamentos e materiais. Sua finalidade imediata é a organização e o controle do processo de trabalho e a mediata a de favorecer o cuidar para a cura.

Reforçando a idéia de controle do processo de trabalho na enfermagem, encontra-se descrito, que assim como o médico está em posição central e dominante sobre os demais profissionais de saúde no modelo clínico, a enfermeira também desenvolve uma relação de dominação sobre os auxiliares, através da divisão técnica e social do trabalho, com pode- res que a diferenciam dos seus subordinados, reproduzindo um modo de ação delineado pelo modelo tradicional ${ }^{(10)}$.

Conforme visto, embora o modelo clínico tenha fortes influências na enfermagem, cabe colocar que outra vertente que emergiu, com o capitalismo, para dar conta das necessidades de saúde das sociedades foi o modelo epidemiológico. Neste, a concepção da doença não é o fenômeno individual centrado no corpo doente, mas a doença como fenômeno coletivo. A necessidade de controlar estes fenômenos se deu historicamente na Europa Ocidental nos séculos XVII, XVIII e XIX, quando as epidemias assolaram os países com muitas mortes. Nesta época, desenvolveu-se na Alemanha, França e Inglaterra o movimento da medicina social, que visou o controle da doença na população. Para isto foram utilizados como instrumentos o saneamento, a higiene social, a política médica, a quarentena, as estatísticas de mortalidade, entre outros. A enfermagem neste modelo é uma parcela do trabalho em saúde em nível coletivo, é também um instrumento de trabalho, porém não mais do trabalho médico, mas sim um dos instrumentos de saúde onde todos os saberes e práticas subordinam-se às necessidades sociais de saúde da população ${ }^{(4)}$.

Os princípios desse modelo seriam a outra forma de poder sobre a vida denominada de bio-política da população, centrado no corpo como espécie, controlando os processos da vida, tais como, a proliferação de doenças, a natalidade e mortalidade. Iniciase assim, a era do bio-poder, onde pela primeira vez, na história do homem, o biológico relaciona-se com o político e os saberes sobre o corpo individual e em relação às populações determinarão o domínio sobre a vida ${ }^{(5)}$.

Diante do exposto sobre os modelos clínico e epidemiológico concorda-se com a idéia de que, ao analisá-los não se verifica incompatibilidade de caráter essencial entre ambos no plano do conhecimento, mas sim que devem ser apreendidos dialeticamente como unidade de contrários. No campo prático, quando se determinam enquanto tecnologia, necessariamente serão pólos contrários, nas dimensões do individual e do coletivo, não devendo esta oposição tendencial ser compreendida como insolúvel, mas como complementariedade do movimento ${ }^{(11)}$.

Embora os dois modelos descritos não sejam excludentes, observa-se que na prática ainda existe, mesmo nos dias de hoje, um predomínio do modelo clínico em relação ao epidemiológico. Ao falar disto, reporta-se à experiência profissional de duas das autoras do presente estudo que, no contexto hospitalar como enfermeiras assistenciais em unidades de tratamento intensivo e pronto-atendimento, verificam a grande influência dos princípios do modelo clínico. Esses serviços, que têm por finalidade tratar pacientes en- 
fermos, dispõem de organização própria, funcionando como ilhas dentro do sistema de saúde, contando com tecnologia avançada e tratamento altamente especializado, o que talvez colabore para que o trabalho de enfermagem seja, muitas vezes, orientado numa única direção, a cura de corpos doentes, enfocando predominantemente $\mathrm{o}$ aspecto biológico e individual, desconsiderando o contexto psicossocial e político, em que estão inseridos os indivíduos que cuidamos.

Ainda sobre as experiências, das autoras referidas no parágrafo anterior, em saúde coletiva se observa, também, a influência da perspectiva biomédica no saber/fazer da enfermagem nesta área de atenção. Exemplificando-se, pode-se dizer que, muitas vezes, as ações desenvolvidas seguem sendo realizadas com maior enfoque na perspectiva individual: a doença e o tratamento médico, o fornecimento das medicações, a triagem dos mais graves, a referência para especialistas e emergências. Desse modo, o enfoque se centra na prevenção/tratamento/reabilitação da doença desconsiderando-a como fenômeno coletivo.
A construção do conhecimento vem acontecendo no processo de trabalho da enfermagem, através de várias formas, aonde o improviso e a criatividade têm sido preponderantes. No entanto, é preciso que esta construção seja potencializada pelo posicionamento crítico diante do conhecimento produzido. Assim, a produção do conhecimento na enfermagem pode se dar no cotidiano de trabalho, decorrendo de interesses e necessidades práticas do dia-a-dia ${ }^{(12)}$.

Em consonância a essas idéias, acredita-se que a produção gerada no cotidiano da enfermagem necessita ir além do improviso e ser documentada, para que assim contribua com o crescimento da profíssão, pois a ciência emerge do discurso do cotidiano e/ou artesanal ${ }^{(13)}$.

A partir dessa revisão quanto à gênese dos modelos clínico e epidemiológico e suas influências na construção do conhecimento da enfermagem, verifica-se que estes são também, a base para a conceituação dos modelos assistenciais vigentes que, por sua vez, apontam para uma tentativa de ruptura de saberes já estabelecidos na construção de novos modelos.

Nas vivências de ensino em saúde coletiva, observa-se que os alunos, recém ingressos no curso de graduação de enfermagem, relatam suas preferências em desenvolver atividades relacionadas a procedimentos, em conhecer a fisiopatologia e tratamento das doenças em detrimento das atividades educativas, dos contatos com as pessoas da comunidade, do contexto onde a comunidade está inserida, de participar de reuniões comunitárias, de realizar ações de escuta, entre outros. Alguns alunos chegam

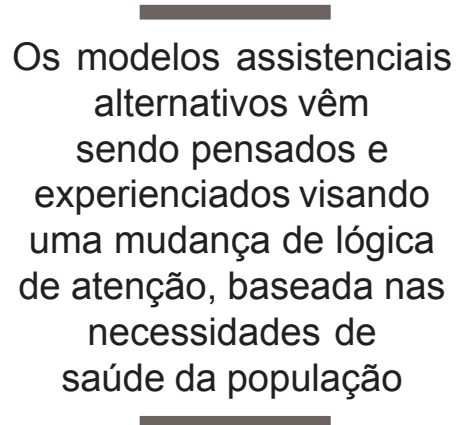

Os Modelos Assistenciais Vigentes no Contexto da Saúde Brasileira

Os modelos assistenciais vigentes, no contexto atual da saúde brasileira, são apresentados como hegemônicos e alternativos. O primeiro está representado fundamentalmente pela concepção médica assistencial privatista e o segundo por propostas alternativas que contemplem os princípios do Sistema Único de Saúde - SUS ${ }^{(3)}$. a relatar que estas últimas atividades poderiam ser executadas pelos agentes comunitários, ficando as ações mais nobres, dentro do posto, para os profissionais de nível superior. Sabe-se que estas posições são reforçadas pelas representações sociais que os estudantes trazem consigo, reforçadas pelas experiências pessoais e familiares, enquanto usuários do sistema e na convivência com alguns profissionais. Há de se considerar também, o enfoque biológico das demais disciplinas iniciais do curso tais como anatomia, fisiologia, patologia, entre outras. Através deste relato, fica claro a necessidade do compromisso das instituições de ensino em modificar estas representações, sem contudo desprezar o aspecto biológico. O desafio é encontrar o ponto de equilíbrio, propiciando a transformação destes referenciais na prática profissional.

Assim, ao se abordar as questões do cotidiano na enfermagem, identifica-se que este é um dos espaços que, por excelência, necessita ser utilizado não apenas para o uso e a socialização do conhecimento já posto, mas também para a sua (re)construção.
Dentre os modelos hegemônicos, encontra-se o médicoassistencial privatista, o qual se baseia na organização dos serviços em conformidade com a demanda espontânea, onde o usuário procura o atendimento de acordo com o seu sofrimento e/ou conhecimento quanto às questões de saúde/ doença. É um modelo que se volta essencialmente para a cura do corpo doente ${ }^{(3)}$.

É abordado ainda, a concepção de que o modelo assistencial sanitarista é uma forma complementar ao anterior, onde as instituições públicas atendem às necessidades de saúde da população, através de campanhas sanitárias e programas de saúde pública. E, tanto as campanhas sanitárias como os programas de saúde se desenvolvem através de administração única e verticalizada ${ }^{(3)}$.

Por outro lado, os modelos assistenciais alternativos vêm sendo pensados e experienciados visando uma mudança de lógica de atenção, baseada nas necessidades de saúde da população, as quais são identificadas mediante estudos epidemiológicos, com uma oferta organizada de serviços planejados, a partir dos referenciais de territorialização, 
integralidade de atenção e impacto epidemiológico. Ao contrário do modelo anterior, o planejamento das ações envolve um processo descentralizado onde as instituições de saúde devem garantir certa racionalidade na utilização dos recursos disponíveis, o alcance dos objetivos definidos e a participação de segmentos sociais interessados. As idéias desse modelo são ilustradas pelas experiências de vigilância em saúde, ações programáticas em saúde e cidades saudáveis, entre outras ${ }^{(3)}$

O Programa de Agentes Comunitários de Saúde (PACS) e o Programa de Saúde da Família (PSF), apesar de serem modelos de atenção hegemônicos, propõem uma oferta organizada de atenção à saúde e não apenas o atendimento da demanda espontânea ${ }^{(3)}$. Esses, poderão reorientar o sistema de saúde, à medida em que deixarem de ter uma gestão verticalizada e aproximarem-se do modelo de intervenção da vigilância à saúde.

Esses programas, embora tenham sido propostos numa perspectiva de mudança de modelo assistencial, são incapazes de atingir este objetivo. Pois, a inversão do modelo assistencial exige mudanças estruturais muito mais abrangentes do que a intervenção dos profissionais ${ }^{(14)}$.

A despeito desses problemas há de se considerar a valorização dos profissionais enfermeiros na estrutura e funcionamento desses programas e as possibilidades de utilizarem este espaço para a construção de novos saberes/fazeres na enfermagem brasileira.

\section{OS MODELOS ASSISTENCIAIS ALTERNATIVOS E A CONSTRUÇÃO DO CONHECIMENTO DA ENFERMAGEM}

O nascimento de uma disciplina científica é uma nova maneira de considerar o mundo, que se estrutura em ressonância com as condições culturais, econômicas e sociais de cada época. Em torno de cada disciplina científica existem regras, princípios, estruturas mentais, instrumentos, normas culturais e/ou práticas, que organizam o mundo antes de seu estudo mais aprofundado ${ }^{(13)}$. Desta forma, existem momentos em que as evidências de um paradigma são colocadas em questão, de acordo com o tempo e o momento vividos.

O paradigma norteador da medicina científica ocidental se caracteriza, historicamente, por privilegiar o diagnóstico da doença e, em conseqüência, o profissional da equipe de saúde mais próximo, o médico, com uma tendência em menosprezar o trabalho de outros profissionais como os enfermeiros. Nesta lógica do atendimento da doença, o paradigma veicula uma série de escolhas de prioridade, como por exemplo, a da cura sobre a higiene e o bem viver, do corpo sobre a psicologia, das especializações sobre a medicina geral, e assim por diante, determinando escolhas políticas e econômicas ${ }^{(13)}$.
No contexto da saúde brasileira, mais especificamente no que diz respeito às suas políticas norteadoras, observase uma proposta de mudança de paradigma relacionada aos modelos assistenciais, com o advento da Reforma Sanitária, a qual propôs novos conceitos que foram firmados na Constituição Federal de 1988, através do Sistema Único de Saúde (SUS), em seus princípios de integralidade, universalidade e equidade.

Nesse sentido, as intervenções em saúde coletiva devem enfocar as relações dos sujeitos no seu cotidiano, superando a visão da coletividade como uma coleção de indivíduos homogêneos, e onde o objeto da ação deixa de ser o corpo biológico para ser os corpos sociais no processo saúde-doença ${ }^{(15)}$.

Atualmente, os modelos assistenciais que contemplam os preceitos da Reforma Sanitária e do SUS são os definidos como alternativos ${ }^{(3)}$. Nesta perspectiva observa-se que os enfermeiros dispõem de uma oportunidade ímpar para a construção de novas tecnologias de trabalho. Assim, alia-se à proposição de que o desafio da enfermagem é o de concretizar, na prática técnica, social e política, a ideologização e institucionalização de novos fundamentos para a práxis da enfermagem, como o cuidar para uma vida plena e digna, direito de todo o cidadão ${ }^{(14)}$.

Dessa forma, acredita-se que um dos caminhos a serem trilhados pela enfermagem seria assumir esse novo desafio na sua prática cotidiana, superando a utilização predominante dos conceitos do modelo biomédico e de sua tecnologia no tratamento da doença, no cuidado de enfermagem dispensado aos usuários dos serviços de saúde. É claro que as representações hegemônicas pesam nesta opção, onde muitos enfermeiros têm se sentido valorizados ao serem responsáveis por tomadas de decisões com a clientela, no que tange às abordagens clínicas. Mas será por aí o caminho? Ou estar-se-á assim, a reforçar o modelo tradicional?

Legalmente e operacionalmente os princípios estão postos, mas tem-se que ter a coragem de enfrentar esse desafio, de colocar em prática o que, muitas vezes, vê-se ser dito como teoria, de inovar em processos já instituídos e propor rupturas no saber já estruturado. Pois, não existe saber acabado e definitivo ${ }^{(16)}$ e o conhecimento na enfermagem não é limitado por fronteiras, mas necessário é saber aplicá-lo, considerando variáveis e historicidade do contexto.

Além de considerar as possibilidades de ruptura e construção de novos conhecimentos, deve-se levar em consideração o compromisso social do profissional, já que qualquer saber expressivo e produtivo deve ser o que tenha um compromisso e o empenho em fazer diferença significante nas vidas dos clientes e comunidades a quem servimos ${ }^{(16)}$.

O momento proporciona trabalhar com a comunidade e com a promoção da saúde, construindo-se novos saberes 
de enfermagem não menos qualificados, mas pautados numa ótica diversa da prevalente. Também para a área hospitalar estes conhecimentos podem ser transpostos, de modo a permitir uma mudança na lógica de atenção, onde o enfoque pode deixar de ser apenas o tratamento da doença, para contemplar uma questão mais abrangente em que o indivíduo, que se encontra momentaneamente doente, após retornará para o contexto social do qual faz parte.

Nessa direção, utiliza-se a proposta de desenvolvimento de tecnologias leves e, a importância em construirmos espaços interseçores entre o usuário e o trabalhador produtor do ato. Processo este, que pode ser construído para além da carência e falta de algo, mas na dimensão de um sujeito que deseja positivamente existir. Isto tudo, pautado numa ótica pela ética do compromisso com a vida e expressas em ato nas dimensões assistenciais do trabalho em saúde, como a relação de acolhimento, a criação do vínculo, a produção da resolutividade e a criação de maiores graus de autonomia, no modo das pessoas andarem a vida ${ }^{(17)}$.

Assim sendo, estratégias como o acolhimento que, muitas vezes, é relegado apenas aos auxiliares de enfermagem das unidades de saúde, ou que representam uma mera continuidade nas atividades de triagem travestidas de um nome atualizado, pode representar uma oportunidade de vínculo entre o enfermeiro e a clientela, para além da queixa da doença, favorecendo o estabelecimento de sentimentos de confiança e de sentir-se ouvido em suas necessidades e expectativas $^{(18)}$. Do mesmo modo, a enfermeira deve estar inserida na equipe de saúde, assumindo sua parcela de responsabilidade na atenção direta à clientela, realizando atividades junto a grupos de apoio, visitas domiciliares e consultas de enfermagem (nem pré, nem pós-consulta médica). Pode ainda, tomar frente nas ações de promoção da saúde, invertendo as prioridades em relação às atividades burocráticas e a predominância do papel administrativo ${ }^{(19)}$ que, muitas vezes, os enfermeiros assumem para si, porque não há quem os faça. Por que o enfermeiro é quem deve assumir estes encargos? A mesma justificativa de que não há pessoal, também é utilizada pelos profissionais da área da saúde, para que as ações de promoção não possam ser feitas, porém estas são muito mais resolutivas e propiciam mais reconhecimento profissional do que tomar para si os encargos burocráticos.

É necessário que a enfermagem se questione sobre o impacto de suas ações e assuma na construção de uma prática interdisciplinar, o seu núcleo de competência e responsabilidade, o cuidado ${ }^{(15)}$.

A busca de estratégias resolutivas passa necessariamente pela forma de atuação do enfermeiro, que necessita usar o seu conhecimento e autonomia profissional junto à clientela onde a resolutividade não deve ser entendida apenas na perspectiva da doença, mas também no sentido de promoção de saúde.

Retomando a idéia da valorização dos espaços interseçores se acredita, entretanto, que esta alternativa não deve significar a migração para o polo contrário, ao negarse ou menosprezar-se o conhecimento clínico ${ }^{(11)}$. Pensa-se ser necessário poder se movimentar entre os dois campos, valorizando as questões objetivas e subjetivas do andar da vida. Esta perspectiva não deve se dar apenas no contexto da atenção básica, mas também nos cenários dos demais níveis de atenção, guardadas as suas especificidades.

O saber da enfermagem, aliado aos modelos assistenciais alternativos existe de alguma forma, pois em suas práticas cotidianas, muitos profissionais desenvolvem ações que contemplam as idéias norteadoras dos mesmos, porém, ainda não se encontram legitimadas para a construção do saber. Deste modo, ao questionar-se quanto a existência de um saber específico da enfermagem reportase às idéias de que o objeto de uma disciplina não existe antes da existência da própria disciplina, mas é construído por ela. E ainda, que uma disciplina científica não é definida pelo objeto que estuda, mas sim, é ela que o determina $^{(13)}$ e, na sua evolução este poderá variar e se transformar.

\section{CONSIDERAÇÕES FINAIS}

Esta reflexão enfoca as origens e principais características dos modelos clínico e epidemiológico e seus nexos com os mode-

los assistenciais vigentes, no sistema de saúde brasileiro, e a inserção da construção do conhecimento da enfermagem neste contexto. Nesta perspectiva, as autoras propõem um repensar quanto ao saber/fazer da enfermagem, indo além do conhecimento preestabelecido pelos modelos tradicionais. Pensam que a ampliação do campo das ações de enfermagem à saúde passa necessariamente por assumir os referenciais da Reforma Sanitária nesta construção, assumindo estrategicamente este espaço colocado, apoiado tanto nestes referenciais como nos princípios legais que o apóiam. Para isto, cabe à enfermagem valorizar e buscar o saber popular, o controle social, a promoção da saúde do sujeito individual e coletivo, sem romper com suas conexões sociais, (re)definindo assim, seus instrumentos e objeto de trabalho.

Apreender essas necessidades das quais tanto se fala, mas que ainda não se consegue transitar efetivamente no sentido de atendê-las, provavelmente, por ser um caminho difícil, tanto em relação a clientela como aos profissionais (principalmente), é que talvez seja o maior desafio, exigindo consciência, comprometimento e vontade de mudar. 
(1) Almeida MCP, Silva EM, Mishima, SM, Villa TCS. Os determinantes dos modelos assistenciais e a qualificação da força de trabalho em enfermagem. In: Anais do $48^{\circ}$ Congresso Brasileiro de Enfermagem; 1996 out. 6-11; São Paulo. São Paulo: ABEn-Seção-SP; 1996. p. 142-9.

(2) Melo Cm. Modelos assistenciais: razões para fazer pensar a enfermagem brasileira. In: Anais do $48^{\circ}$ Congresso Brasileiro de Enfermagem; 1996 out. 6-11; São Paulo. São Paulo: ABEnSeção-SP; 1996. p. 166-71.

(3) Paim JA. Modelos de atenção e vigilância da saúde. In: Rouquaryol MZ, Almeida FN. Epidemiologia e saúde. $6^{\mathrm{a}}$ ed. Rio de Janeiro: MEDSI; 2003. p. 567-86.

(4) Almeida MCP, Rocha SMM. O trabalho de enfermagem. São Paulo: Cortez; 1997. Considerações sobre a enfermagem enquanto trabalho; p. 15-26.

(5) Foucault M. História da sexualidade I: a vontade de saber. $14^{\mathrm{a}}$ ed. Rio de Janeiro: Graal; 2001.

(6) Capra F. O ponto de mutação. São Paulo: Cultrix; 1982.

(7) Nightingale F. Notas sobre enfermagem. São Paulo: Cortez; 1989.

(8) Castellanos BEP. O trabalho do enfermeiro - a procura e o encontro de um caminho para seu estudo: da abordagem mecânico-funcionalista a pesquisa emancipatória [tese]. São Paulo. Escola de Enfermagem da USP; 1987.

(9) Waldow VR. Cuidado humano: o resgate necessário. Porto Alegre: Sagra Luzzatto; 1998.

(10) Lima MAD, Almeida MCP. O trabalho de enfermagem na produção de cuidados de saúde no modelo clínico. Rev Gaúcha Enferm. 1999; 20(n. esp):86-101.
(11) Gonçalves MRB. Tecnologia e organização social das práticas de saúde: características tecnológicas de processo de trabalho na rede estadual de centros de saúde de São Paulo. São Paulo: Hucitec/Abrasco; 1994.

(12) Alves DB. Produção/reprodução do conhecimento no trabalho na enfermagem: o conhecimento como forma de estar no mundo. In: Garcia TR, Pagliuca LMF, organizadoras. A construção do conhecimento em enfermagem: coletânea de trabalhos. Fortaleza: Rene; 1998. p. 93-114.

(13) Fourez G. O método científico: a ciência como disciplina intelectual. In: Fourez G. A construção das ciências. Introdução à filosofia e a ética das ciências. São Paulo: UNESP; 1995. p. $103-43$.

(14) Antunes MJ, Egry E. O programa saúde da família e a reconstrução da atenção básica no SUS: a contribuição da enfermagem brasileira. Rev Bras Enferm. 2001; 54(1):98-107.

(15) Matumoto S, Mishima S, Pinto I. Saúde coletiva: um desafio para a enfermagem. Cad Saúde Pública. 2001;1(17):233-41.

(16) Souza MF. Contribuição para a construção do conhecimento em enfermagem no Brasil. In: Garcia TR, Pagliuca LMF, organizadoras. A construção do conhecimento em enfermagem: coletânea de trabalhos. Fortaleza: Rene; 1998. p. 51-63.

(17) Merhy E, Onocko R. Praxis en salud: un desafio para lo publico. Buenos Aires: Lugar; 1997.

(18) Fracolli LA, Zoboli, ELCP. Descrição e análise do acolhimento: uma contribuição para o programa de saúde da família. Rev Esc Enferm USP. 2004;38(2):143-51.

(19) Adami NP. A função assistencial exercida pela enfermeira nos Centros de Saúde da Secretaria de Saúde do Estado de São Paulo. Rev Esc Enferm USP. 1980;14(1):63-72. 